\title{
Feminismos no nordeste brasileiro: Histórias, memórias e práticas políticas
}

\author{
Mary Ferreira \\ Universidade Federal do Maranhão, São Luís do Maranhão, Brasil. \\ Email: mmulher13@hotmail.com
}

\begin{abstract}
Resumo: O feminismo no Brasil é remanescente do movimento sufragista que eclode no século XIX, tem suas primeiras “vitórias” no início do século XX e mudanças substanciais no final desse século. Tais mudanças, entretanto, não se deram de forma natural, uma vez que mudanças sociais são resultantes de processos de luta, reivindicações, mediações e ação permanentes. Ao refletir sobre as memórias do feminismo no Brasil buscamos abrir olhos e mentes que permitam refletir os passos largos que possibilitaram construir agendas consideradas avançadas no contexto brasileiro, ou passos lentos que em determinadas situações parecemos recuar ou os momentos em que não demos passos nenhum, ficamos paradas, apenas refletindo sobre ações articuladas para pensar, planejar e transcender o lugar comum na busca de um presente que permitam as mulheres se constituir como sujeito.

Palavras-chave: feminismo, Nordeste, Brasil, memória, ação feminista, políticas públicas.
\end{abstract}

\section{Feminismos en el noreste de Brasil: Historias, memorias y prácticas políticas}

Resumen: El feminismo en el Brasil es una reminiscencia del movimiento sufragista que entra en erupción en el siglo XIX, tiene sus primeras "victorias" a principios del siglo XX y obtiene cambios sustanciales en la final de este siglo. Estos cambios, sin embargo, no tienen una forma natural, ya que los cambios son el resultado de procesos de lucha, reivindicaciones, mediaciones y acciones permanentes. Al reflexionar sobre los recuerdos del feminismo en Brasil se trata de abrir los ojos y la mente para hacer posible reflejar los largos pasos que permitieron construir agendas consideradas avanzadas en el contexto brasileño, o los pasos lentos de ciertas situaciones en que se pareció dar marcha atrás o los momentos en que no se dio ningún paso, se produjo una detención, solamente reflexionando sobre acciones articuladas para pensar, planificar y trascender el lugar común en busca de un presente que permita a las mujeres constituirse como sujeto.

Palabras clave: Feminismo, Nordeste, Brasil, memoria, acción feminista, políticas públicas.

\section{Feminism in northeastern Brazil: Histories, memories and political practices}

\begin{abstract}
Feminism in Brazil is reminiscent of the suffrage movement that hatch in the nineteenth century, had its first "victories" in the early twentieth century and substantial changes at the end of this century. Such changes, however, do not have a natural path, since social changes are the result of processes of
\end{abstract}


struggle, reivindications, mediations and permanent actions. When thinking about the memories of feminism in Brazil one seeks to open eyes and minds in order to make it possible to show the long steps taken that enable to crate agendas considered advanced in the Brazilian context, or the slow steps in certain situations that resembled a retreat, or times when no steps were taken, and a stop took place, just meditating on coordinated actions in order to think, plan and transcend the common place in search for a time that will allow women to become a subject. policies.

Key words: feminism, Northeast, Brazil, memory, feminist action, public

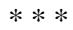

\section{Introdução}

O feminismo no Brasil tem nuances que reforçam sua diversidade, particularidades e correntes. Sua história está representada a partir das feministas que vivenciaram múltiplas práticas políticas traduzidas em ações e mediações que favoreceram conquistas e impasses. Ao rememorar fatos dessa história descortinamos um passado que se projeta no presente, antecipando fatos que antes pareciam inalcançáveis e nos remetem a outros, que ficaram perdidos nos embates solitários, e nas lutas, muitas delas, silenciadas pela obscuridade de uma sociedade que se fez surda, quando os gritos e as provocações das feministas ultrapassaram os espaços do permitidos.

Ao buscar os fios para construir uma memória que dê conta de reconstituir a história do feminismo no Nordeste com um olhar mais atento no Estado do Maranhão busco em Pollack (1992) os elementos para constituir parte da memória individual e coletiva das feministas que viveram os acontecimentos de um momento histórico em que cada uma se permitiu e transgrediu naquilo que o feminismo possibilitou individual e coletivamente, para construir uma história na qual as feministas apontaram novas práticas políticas e novos modos de pensar a sociedade tendo as mulheres como sujeito.

A história das mulheres é uma história construída com silêncios, enfatiza Perrot (2005), porém a histórias das feministas brasileiras rompe com os silêncios impostos secularmente e torna a luta como um lugar de protestos e de festa. Éramos poucas, sempre fomos! Mas, a irreverência nos tornava multidão. Assim foi em vários Estados do Norte e Nordeste brasileiro: Maranhão, Pernambuco, Bahia, Paraíba e posteriormente Pará, Ceará, Rio Grande do Norte, Sergipe. Recuperar parte desta história é o que me proponho nesta comunicação.

Parto de estudo desenvolvido no mestrado em Políticas Públicas cuja pesquisa versa sobre a ação do Grupo de Mulheres da Ilha, pioneiro dos feminismos no Maranhão para estabelecer um diálogo com outros grupos que protagonizaram lutas e conquistas que contribuíram para mudanças substanciais nas relações de gênero na sociedade maranhense. 


\section{A Memória como elemento de reconstruir novas leituras da realidade}

Pensar os feminismos no Brasil é refletir a partir da memória não apenas dos acontecimentos trazidos pela história, mas também das palavras concebidas pelas imagens guardadas e traduzidas em fatos que ao passar "pelos sentidos, gravaram no espírito uma espécie de vestígio". São esses vestígios que muitas vezes nos permitem desvendar fatos e acontecimentos que se para alguns passaram despercebidos, para outros estão imbricados com suas histórias e suas perspectivas de vida.

Os estudos sobre memória permitem ampliar a noção de pertencimento na realidade em que o individuo está inserido e valorizar fenômenos e acontecimentos que permitem reescrever uma nova história com fatos e sujeitos que esclarecem e enriquecem novas formas de refletir sobre a realidade. O caráter coletivo da memória funciona como um suporte social doado por grupos pregressos e contemporâneos, especialmente em condições que promovem uma participação enraizada por mulheres e homens no meio coletivo. A memória integra o trabalho de elaboração psíquica, reconstrói o ponto de fricção de sua experiência no mundo, por sua recorrente inscrição na subjetividade que o sujeito poderá caminhar mais ou menos de forma bem sucedido para a liberação de novas significações do vivido.

Pollack (1992) enumera os elementos constitutivos da memória individual ou coletiva como sendo os acontecimentos vividos por cada pessoa ou em grupo no sentido de construir o coletivo associado à idéia de pertencimento. Os acontecimentos traduzem a memória das pessoas, dos atores sociais e finalmente os lugares de memória, cujos acontecimentos ou lembrança permitem reconstruir fatos para pensar novas histórias. A memória, segundo Pollack, é na maioria das vezes herdada não se referindo apenas a vida física de uma pessoa, mas está presente nas construções coletivas costuradas de pequenos e grandes acontecimentos, visto por cada sujeito em determinada época ou lugar.

Os estudos sobre memória permitem alterar e modificar fatos descritos a partir de novos olhares que pode promover mudanças sociais, a partir do tempo de sua organização em função das preocupações pessoais e políticas dos vários momentos vivenciados pelos sujeitos, que possibilita reconstruir o fenômeno ou acontecimento, baseado em novos fatos.

Nos estudos sobre memória é importante observar que sua concepção permite coletivizar fatos e reescrever a história de maneira plural e democrática; como uma alternativa àquela considerada originária e oficial que em muitas situações é concebida como a história dos vencedores, pois reproduz a visão daqueles que estão no exercício do poder, os dominadores. O desafio dos estudos sobre memória é fazer com que as experiências silenciadas, esquecidas, suprimidas ou privadas da população se reencontrem com a dimensão histórica a partir das participações coletivas, de novos 
sujeitos que apresentam possibilidade de constituição de espaços públicos diferenciados, como espaços de memória e de experiências vividas e partilhadas. Seu objetivo não é apenas "registrar fatos, à maneira da historiografia oficial, mas de contribuir ativamente para que no nosso presente não ocorra o esquecimento da tragédia” (Bruni, 2007:17)

Para Pollak (1989:9) o trabalho de memória "reinterpreta incessantemente o passado em função dos combates do presente e do futuro,” uma vez que a constituição da memória cresce com a história, que por sua vez a sustenta, busca livrar o passado para servir o presente e o futuro. O presente é visto por Bruni (2007:17) como "lugar que permite a crítica à história recente, mas ao mesmo tempo como lugar que se podem detectar os mecanismos pelos quais esta vai sendo aos poucos esquecida, neutralizada e posta em estado letárgico, isto é silenciada”.

Daí a importância de reconstruir o esquecimento a partir de nossas lembranças, experiências e vivências que deram aos feminismos brasileiros o papel de vanguarda na constituição de uma história que teve como protagonistas todas nós presentes neste Seminário e muitas companheiras que deixaram suas marcas na luta cotidiana para dar voz as mulheres e permitir dessa maneira reescrever as histórias dos feminismos nas suas várias dimensões considerando seus vários lugares, suas várias Regiões, tempos e momentos cujas singularidades cada uma protagonizou.

\section{Memórias e Feminismos no Nordeste}

A história dos feminismos no Nordeste tem marcos semelhantes àquilo que se constituiu como feminismos no Sul e Sudeste. Da necessidade de se engajar na luta pela redemocratização do País nasce a necessidade de articular a luta feminista levada pelo desejo de discutir e se contrapor a um discurso que excluía as mulheres da condição de sujeito.

Os primeiros grupos criados em São Paulo no início dos anos setenta são reforçados pelos acontecimentos do Ano Internacional da Mulher que abre caminhos para refletir sobre as mulheres em variados contextos. Estávamos em 1975 e o mundo percebe a presença das mulheres e a necessidade de refletir seus problemas a partir delas própria. Das pioneiras sufragistas na qual se destaca Bertha Lutz, em São Paulo, Leolinda Dalton na Bahia, Eneida de Moraes no Pará e Violeta Campos, no Maranhão, muitas mulheres no início do Século XX deram um novo sentido a história ao mostrar os acontecimentos a partir de suas vivências, lutas e que estas vivências traduzem uma forma de retratar os fatos de cada momento do presente.

O que caracteriza a dimensão social e política de um movimento é sua capacidade de transgredir, de trazer fatos políticos, de recompor momentos que dão novo sentido a realidade. Os movimentos feministas no Brasil como enfatizamos, emerge na década de setenta articulados com as lutas pela anistia e pela abertura política. As ações dos grupos num primeiro 
momento concentraram-se no eixo São Paulo e Rio de Janeiro, posteriormente foram irradiando para os Estados do Nordeste, Sul, Norte e Centro Oeste. As dificuldades de expandir as fronteiras desse movimento dado às dimensões continentais do País foram inúmeras, tais dificuldades, porém, não foram maiores do que os desejos das feministas de socializar idéias, conteúdos, que permitiram e possibilitaram a visibilidade de questão até então despercebidas da sociedade. A ação dos movimentos feminista trouxe a público o universo das mulheres, suas inquietações e bandeiras de luta.

No Norte e Nordeste esse movimento teve ressonância através de vários grupos entre os quais o Ação Mulher que surge em Recife em 1978 “como um grupo de reflexão e autoconsciência” (Arrazola, 2000:79), o Centro da Mulher de João Pessoa, que foi criado em 1979 e posteriormente, passou a ser denominado "Grupo feminista Maria Mulher ao assumir uma identidade feminista propriamente dita”. (Rabay, 2000:92). No ano seguinte (1980) em São Luís nasce o Grupo de Mulheres da Ilha, em um momento histórico em que o Maranhão vivia a utopia da união das esquerdas através do movimento “Oposição pra Valer”. É um período marcado pela eclosão de vários movimentos: pela moradia, contra a carestia, em defesa de Ilha, direitos humanos, nasce ainda neste período o Partido dos Trabalhadores enfatiza Ferreira (2007).

A característica geral desses grupos, a exemplo do Grupo de Mulheres da Ilha era a forma autônoma como articularam suas ações políticas que lhes dava uma independência na transgressão de valores, na manifestação de idéias que se por um lado as diferenciavam, por outro as estigmatizavam e ao mesmo tempo as excluíam. A partir dos anos de 1980, começam a surgir outros grupos e muitos se transformam em as Organizações não governamentais, sendo o SOS - Corpo de Recife um dos pioneiros, fundado em 1981, posteriormente as Mulheres da Ilha também tornou-se ONG, em João Pessoa emergem outros grupos a exemplo do Cunhã, o Centro da Mulher 8 de Março, os núcleos de pesquisa nas universidade que passam a articular na pesquisa a necessidade de aprofundar os estudos sobre as desigualdades de gênero na Ciência.

Em Pernambuco há uma efervescência de grupos criados na década de oitenta: Centro de Mulheres do Cabo, Cais do Parto, Viva Mulher, e os vários núcleos de mulheres ligados a Universidade Rural de Pernambuco, da federal de Pernambuco e a Fundação Joaquim Nabuco. No Rio Grande do Norte merece registro a atuação do Grupo Feminista Leila Diniz que tem atuado de forma mais significativa em meados dos anos noventa tendo como foco de atuação a questão de violência, emerge também neste Estado o Grupo de Mulheres pesquisadoras na Universidade Federal de Pernambuco.

A história desses Grupos e de tantos outros, revela um lado da história das lutas libertárias no Brasil ainda pouco evidenciado nas pesquisas nesse campo. A ausência de estudos que recupere a dimensão desses grupos e ou a ação das feministas do norte e nordeste no processo de reconhecimento 
da identidade e cidadania das brasileiras, nas articulações e implementação de políticas públicas nos levou a publicar em 2007 o Livro “As Caetanas vão à luta: feminismo e políticas públicas no Maranhão fruto de estudo desenvolvido no Programa de Pós-Graduação, em Políticas Públicas UFMA, no qual recupero parte de uma história protagonizada por maranhenses, gaúchas, cariocas, paulistas, brancas e negras que possibilitaram ao Grupo de Mulheres da Ilha ser a vanguarda em momento histórico no Maranhão.

Cabe neste momento traçar alguns elementos que possam nortear a constituição da Memória desse movimento notadamente nesta Região geográfica a fim de que os fatos trazidos neste tempo presente que é um tempo "propício para desenterrar histórias, biografias, autobiografias, diários, cartas, enfim todo o farto arsenal que guarda o conhecimento de trajetórias de vida, de experiências individuais e coletiva” (Viana, 2004:147) que nos permite contrapor as temporalidades fugazes, das universidades que nos invisibiliza, nos tira a condição de sujeitos e protagonistas de uma história que também tem nossas lutas, energias e emoções.

O feminismo na Região Norte e Nordeste ainda está por ser escrito e inscrito nas páginas da história brasileira, a fim de que a memória das protagonistas e dos grupos, assim como suas contribuições para compor e recompor a memória e fazer jus à história. Tais assertivas podem ser evidenciadas quando da realização da Mesa Redonda "30 Anos do Feminismo no Brasil” realizado em 2006 na ANPOCS. Surpreendentemente não registramos nenhuma feminista da Região Norte nem Nordeste nesta mesa. A não presença e o não registro nos leva a refletir de que lugares cada pesquisadora fala e interpreta o feminismo no Brasil. A maioria dos estudos refletem um feminismo que ainda não ultrapassou as fronteiras do eixo São Paulo - Rio de Janeiro e dá leves saltos em Minas Gerais, Santa Catarina, Porto Alegre. E os outros feminismos? Porque permaneceram por tanto tempo invisíveis? Porque no presente ainda não conseguem ser protagonizadores de uma nova história?

Cabe nessa mesa de forma breve contribuir para lembrar, rememorar historicamente os muitos feminismos e as muitas feministas desse lado esquecido do Brasil e as construções e repercussões que alguns desses grupos foram capazes de promover ao longo da história.

É importante mencionar que nossas memórias são construídas a partir de reflexões teóricas, de vivências na Rede Saúde de Saúde e Direitos Reprodutivos no qual atuei como membro do Conselho Diretor, na Articulação de Mulheres Brasileira como integrante e na Rede Feminista Norte e Nordeste de Estudos e Pesquisa sobre Mulher e Relações de Gênero - REDOR, no qual tive a oportunidade de presidir no período de 20072009, e nas muitas observações, nos inúmeros eventos que tive oportunidade de participar, seja na condição de conferencista, ou na condição de ouvinte nos debates realizados desde 1980 quando ainda aprendia os primeiros passos do ser feminista. 
O feminismo do Nordeste na sua fase inicial nasce nos Estados da Bahia, Pernambuco, Paraíba, Maranhão como os mais articulados com os ares da Região Sudeste em especial São Paulo e Rio de Janeiro. O Brasil Mulher como o pioneiro na Bahia protagonizado por feministas como Ana Alice Costa, foram as responsáveis pela criação de um novo momento político nesse Estado. Posteriormente essas feministas criam o Núcleo de Estudos Interdisciplinar sobre a Mulher - NEIM que em 2009 comemorou 25 anos de existência e foi o responsável pela inserção do tema na universidade da Bahia e o incentivador e aglutinador da temática nas universidades do Nordeste e Norte, culminando com a criação da REDOR em 1992.

A importância do NEIM pode ser avaliada pela extensa produção acadêmica, pela coordenação de foros importantes que permitiram descentralizar o feminismo da Região Sudeste e trazer para o cenário acadêmico e político as particularidades de feminismo pautado em Regiões marcadas pela exclusão. Os resultados dessa ação política e acadêmica são as conquistas obtidas nas recentes pós-graduações criadas, nas graduações com a abordagem de gênero e na abertura de um amplo legue de estudos e pesquisa que permitem ampliar os sentidos de construção da mulher como sujeito de estudo e da história.

Em Pernambuco os feminismos segundo Arrazola (2000) têm seus registros históricos em 1978, quando se forma o primeiro grupo feminista: “Ação Mulher” cujas militantes a exemplo do Estado da Bahia, do Rio de Janeiro e do Estado de São Paulo são remanescente dos movimentos de esquerda que combatiam a ditadura, muitas ainda no exílio, outras em Recife. Essas mulheres se aliam para criar o Grupo Ação Mulher, esse grupo a, exemplo, das Mulheres da Ilha em São Luís manteve sua autonomia em relação aos partidos seguindo assim uma proposta feminista que irá refletir posteriormente em vários grupos. "Diferentemente ao que se deu com outros grupos, a exemplo do Brasil Mulher, existente em outros Estados, como em São Paulo, vinculado ao Partido Comunista” (Arrazola, 2000:79) ou a União de Mulheres em São Luís ligado ao Partido Comunista do Brasil/PCdoB.

O Ação Mulher desaparece dois anos depois de sua criação. Segundo Arrazola (2000:80) "os conflitos internos referentes a questão temática e de ação (emprego e renda x corpo, sexualidade, auto-exame)” além dos impasses acerca dos métodos de trabalho e as influências partidárias contribuíram para a dissolução do Grupo. Mas segundo a autora:

[...] dessa ruptura surgiram outros grupos: a casa da Mulher do Nordeste, privilegiando a temática trabalho, e o S.O.S Corpo privilegiando [o debate sobre] corpo e saúde... posteriormente, surgem o Centro das Mulheres do Cabo, Curumim, Cais do Parto, Viva Maria, Coletivo Mulher Vida[...] (Arrazola, 2000, p.82).

Dos muitos desafios apontados pelas feministas pernambucanas Arrozola (2000:83) destaca "o desenvolvimento de uma estratégia de 
reconhecimento da autoria feminista” já que muitas conquistas no atual contexto não estão associadas à luta empreendida pelas feministas ao longo das ultimas décadas. Esses desafios passaram a ser articulados pelo Fórum de Mulheres de Pernambuco criado em finais da década de oitenta no qual se agregam todas as organizações não governamentais feministas e demais expressões do movimento organizado de mulheres que se constituem como um centro importante de "debate das questões de das mulheres no Estado e da articulação das mesmas com o feminismo nacional” (Chaves; Severien, 2006:95).

O feminismo na Paraíba tem seu segundo momento em 1979 com a criação do Centro da Mulher de João Pessoa, embora ainda não caracterizado como um grupo feminista foi gradativamente assumindo papéis políticos. Em 1980 passa a ser denominado grupo Maria Mulher, agregando em sua maioria professores e estudantes universitárias que participaram de diversas manifestações políticas.

Apesar das diversas oposições que sofria também nas fileiras da chamada esquerda brasileira na época, o Movimento feminista buscou alianças com os movimentos populares executando tarefas na área de educação e assessoria à sociedade civil e pobre (Rabay, 2000:92).

Ao grupo Maria Mulher se somaram outros grupos posteriormente criados como O Centro 8 de Março, o Cunhã, que tornaram-se ONGs e protagonizaram muitas ações e articulações nacionais entre as quais a criação da Articulação de Mulheres Brasileiras, a coordenação nacional da campanha pela descriminalização do aborto entre outras ações.

\section{Algumas reflexões para compreender a história dos feminismos no Maranhão}

No Maranhão o movimento feminista nasce com o grupo de Mulheres da Ilha que se constituiu em julho de 1980 como um espaço de reflexão e aprofundamento das questões levantadas no Curso de Extensão Mulher na Sociedade Brasileira promovido pela Universidade Federal do Maranhão ministrado pela Prof ${ }^{a}$ Marisa Correa da UNICAMP. “Às reflexões desse curso se aliaram várias outras mulheres, em busca de espaço em que pudessem se exprimir mais livremente” (Ferreira, 1999: 93).

Segundo Ferreira (2008) outros grupos emergiram após a criação do Grupo de Mulheres da Ilha na década de oitenta com diferentes inspirações, dentre eles: o Grupo de Mulheres 8 de Março, Grupo de Mulheres Mãe Andressa, União de Mulheres, Espaço Mulher, Grupo Viva Maria, Mulheres do PDT. Na década de noventa surge a Pastoral da Mulher, o Grupo Maria Firmina, os Grupos de Estudos nas Universidades, os Departamentos da Mulher nos sindicatos e nos partidos, o Coletivo de Mulheres Trabalhadoras Rurais. A ação desses grupos segundo a professora Florilena 
Aranha "contribui para ampliar o debate, somar esforços em torno de questões comuns que hoje são articulados no Fórum Maranhense de Mulheres que aglutina os grupos em atividades no Estado”. (Ferreira, 2008).

Para compreender melhor esses movimentos no Maranhão ouvimos algumas representantes dos diversos movimentos, entre as quais a professora Florilena Aranha que coordena o Fórum Maranhense de Mulheres, a assistente social Sandra Torres, ex-vice-prefeita coordenadora da Comissão Estadual de Mulheres do Partido Democrático Trabalhista - PDT e outras militantes que nos possibilitaram colher depoimentos que nos permitiu ter uma visão geral sobre o movimento e avaliar sua repercussão no Estado.

O feminismo no Maranhão nasce como movimento social, não homogêneo que questiona a política, o poder, as relações patriarcais e discute teoricamente à mulher como sujeito na sociedade. O diferencial do feminismo é sua autonomia em relação a partidos, igrejas, e sindicatos que lhe dá um tom, uma diferença metodológica. (Ieda Batista, 2006).

Dos muitos grupos criados na década de oitenta, destacamos aqueles que tiveram mais repercussão nas suas articulações: Grupo de Mulheres 8 de Março, Grupo de Mulheres Mãe Andresa, União de Mulheres, Espaço Mulher, Grupo Viva Maria, Mulheres do PDT, Grupo de Mulheres do Ninho. As ações desses grupos foram muitas delas contínuas como, por exemplo, as ações das Mulheres da Ilha, do Mãe Andresa, da União de Mulheres, das Mulheres do PDT, porém alguns grupos tiveram vida curta pois nasceram em uma determinada situação e não conseguiram superar as dificuldades dos impasses e contradições da própria luta. Um exemplo foi o Grupo Viva Maria que nasceu interessado na questão da violência, contribuiu na conquista da Delegacia Especial da Mulher, trabalhando com vivências, prestando assessoria a delegacia da mulher na capacitação do quadro de funcionários da delegacia, finalizando suas atividades nos início dos anos noventa.

Outros grupos que também não tiveram continuidade foram os grupos 8 de Março e o União de Mulheres, ambos mais ligados a partidos ou grupos políticos e que levantaram muitas polêmicas com o Grupo de Mulheres da Ilha. As polêmicas em geral estavam nas velhas "questões gerais e questões específicas” que para as feministas não estavam dissociadas já que não se podia pensar o Estado ou o sistema político sem considerar as questões que diziam e dizem respeito ao gênero.

O feminismo não desvincula a questão de classe das questões de gênero nem das questões étnicas raciais, pois estão vinculadas a relações de poder e dominação que perpassam as relações de sociais. As polêmicas em torno dessas idéias, que também se dava intra grupos, ampliavam o debate desconstruindo os estigmas sobre as mulheres baseadas em diferenças biológicas que enaltecem qualidades associadas ao sexo feminino como: docilidade, sensibilidade, fertilidade, beleza, pureza rebatidos pelas feministas na medida em que propunham romper com a passividade, com o conformismo e a acomodação. 
Essas visões ainda não superadas levaram e levam determinadas mulheres a se autodenominarem "femininas e não feministas" sem considerar que esta afirmação implica a negação das bandeiras históricas defendidas pelas mulheres nos últimos quarenta anos. Ser feminista é “quebrar as barreiras do silêncio imposto pelas estruturas dominantes de gênero e usar permanentemente a voz em defesa dos direitos e no combate as injustiças contra as mulheres” (Ferreira, 2004:2).

O afirmar-se como feminista, porém, e se identificar como tal tem sido um desafio enfrentado pelas mulheres e grupo. Isso é percebido na fala de Fátima da Pastoral da Mulher quando afirma: “falar do Feminismo, é muito pesado, não vejo muito isso, não somos feministas, estamos cobrando um direito que é nosso. Nós ajudamos a sociedade e estamos cobrando o que temos direito".

Mesmo sendo pesado afirmar-se feminista as mulheres estão se identificando com as inúmeras ações desencadeadas por esses grupos que contribuíram para transformar as relações de poder na sociedade a partir da promoção de cursos, oficinas, seminários, amplos debates sobre temas, os mais diversos, da criação de leis que repercutem na vida das mulheres.

Muitos grupos se fecharam como o Espaço Mulher, 8 de Março, União de Mulheres, o Viva Maria, porém as feministas permaneceram fazendo histórias em outros espaços como ilustra Ieda Batista "quem bebe dessa água do feminismo na sua filosofia e prática não fica imune a mudanças" e reforça Marluze Pastor "vários grupos sumiram, mas as pessoas que passaram por ele, mudaram suas vidas e suas atuações, onde elas estão, são diferentes... são outras pessoas”. Assim tem sido as atividades desenvolvidas por Sandra Nascimento remanescente do Grupo Espaço Mulher, hoje pesquisadora da Universidade Federal do Maranhão, voltou sua ação política para o desenvolvimento de estudos e pesquisas na temática gênero. Da mesma forma que Marluze Pastor ${ }^{1}$ desenvolveu a frente do IBAMA um trabalho iniciado no Grupo de Mulheres da Ilha e no Fórum Carajás, voltado para as questões de gênero e meio ambiente no qual analisa os impactos na vida das mulheres.

Dos grupos feministas que desenvolveram atividades sistemáticas e ininterruptas destacamos além do Grupo de Mulheres da Ilha o Grupo de Mulheres Negras Mãe Andresa criado em 1986 que nasce trabalhando com conflitos que polarizaram sua atuação. Para Lucia Dutra eram conflitos advindos da relação de "ser mulher negra no Movimento Negro e ser feminista no Movimento Feminista que é um Movimento que nasce com as mulheres brancas... Passamos como divisionistas, quando queríamos afirmar nossa condição de mulheres negra” (Lucia Dutra, Mesa de Diálogo, 2006). Ao fazer um balanço das ações desse grupo Lucia Gato enfatiza que:

Nestes vinte anos de trabalho nossa grande preocupação hoje é como trabalhar com capacitação, participação nos Conselhos, como ser 
parte integrante e ativa e não um recorte das especificidades da mulher negra. Para nós isso é muito importante, não só uma contra imagem. Partimos de um processo de onde saímos da guetização para o empoderamento,...[...] com o olhar no processo que nos permite trabalhar histórias, lembranças, outros processos de corporalidade, que nem sempre é considerado, mas, que fortalece a mulher negra. Foi uma grande experiência e aprendizagem (Lucia Gato - Mesa de Diálogo, 2006).

São muitas feministas, muitos feminismos e muitas histórias. As experiências apresentadas por Jô Santos que falou pelas mulheres do Partido Democrático Trabalhista - PDT, e as de Luiza do Grupo de Mulheres Negras Maria Firmina criado no final dos anos noventa evidenciou que:

a troca de conhecimentos, de saberes é uma necessidade e que não estamos em campos opostos. Os feminismos no Maranhão hoje passam por isso, aqui estão as reconhecidamente feministas, mas, as demais que estão organizadas”. ( Lourdes Leitão Nunes Rocha, Mesa de Diálogo, 2006).

A fala de Luisa na mesa de diálogo expressa muito bem esses vários feminismos: "Nós não nascemos da academia a gente não tem teoria do feminismo, mas, estamos fazendo feminismo”. (Luisa Mendes, Mesa de Diálogo, 2006).

\section{Desafios para construir um feminismo em tempo presente}

As muitas experiências aqui relatadas dão a dimensão e riqueza do que foi e do que representa este movimento revolucionário como expressou Hobsbawer, Boaventura Santos, Michelle Perrot, Helleieth Saffiotti e tantas outras estudiosas dos movimentos sociais. Falar das influências do feminismo e das perspectivas desse movimento como parte das ações das feministas junto às organizações é rememorar a construção do feminismo no Maranhão e nos Estado do Nordeste desde o início dos anos oitenta quando emerge na maior parte dos estados mencionados. Nessa breve memória foi possível rever fatos da história e caminhos percorridos, pelas feministas cujas influências demarcam a vinculação de cada uma com o feminismo.

O pensamento e a as metodologias feministas expressam um diferencial entre as organizações de mulheres e a prática feminista na medida em que "desafiam e transgridem a ordem estabelecida retirando da invisibilidade e fazendo emergir um novo projeto de sociedade" (Ferreira, 2000:71). O enfoque feminista define a atuação política das feministas e dos grupos quando propõe uma inversão do privado que pode ser analisado pelos discursos e ações apreendidas por cada grupo feministas criado no Nordeste. 
Em cada Estado houve um grupo que foi a vanguarda desse movimento que superou os limites do patriarcado e o conservadorismo que marca as sociedades escravocratas nessa Região. No Maranhão foi as Mulheres da Ilha, em Pernambuco o SOS Corpo, na Bahia o NEIM ampliou os horizontes da academia e desafiam a sociedade na medida em que permanecem atuantes agregando e estimulando a formação de novos grupos.

$\mathrm{Na}$ trajetória de cada um desses grupos são reveladas várias histórias e caminhos percorridos, pelas feministas cujas influências demarcam a vinculação de cada uma com o feminismo, porém as ações das feministas e dos grupos nunca estiveram desvinculadas da atuação nos partidos políticos, nas organizações sindicais, em setores da igreja católica. São histórias que revelam como e em que medida tais processos absorveram, e como o pensamento feminista foi incorporado, trabalhado em suas práticas políticas.

O enfoque feminista define a atuação política das feministas e dos grupos quando propõe uma inversão do privado que pode ser analisado pelos discursos e ações empreendidas por cada grupo. Em se tratando da experiência das feministas do Grupo de Mulheres da Ilha, Ferreira (2006) e Torres enfatizam:

Éramos consideradas um grupo de mulheres burguesas, acadêmicas, porém as ações do Grupo de Mulheres da Ilha tiveram vários desdobramentos dentre elas gostaria de lembrar o trabalho desenvolvido no bairro de São Bernardo em 1982 quando desenvolvemos uma série de atividades a convite do Padre Marcos Passarine com as mulheres daquele Bairro ainda envolvidas no processo de ocupação daquela área. Desse trabalho nos chamava a atenção o interesse das mesmas em discutir saúde, sexualidade, contracepção, prazer embora houvesse uma interferência de grupos partidários de indicar temas relacionados com os problemas do bairro, infraestrutura, política partidária... Respeitamos os desejos das mulheres... (Mary Ferreira, Mesa de Diálogo, 2006).

O Grupo de Mulheres da Ilha foi a matriz, ele nasce e se coloca como feminista. Elas influenciaram muito, através das capacitações. Sempre atuaram no plano da contribuição intelectual. As atividades políticas que realizaram era de cunho essencialmente feminista, pagaram todos os ônus dos preconceitos e estigmas, cumpriu um papel e atuou como um disseminador de idéias junto a várias instâncias como movimento sindical, partidário, nas universidades, junto a trabalhadoras rurais.(Sandra Torres, 2009).

Para Maria Bethânia Ávila a criação do SOS Corpo traduz um momento de inquietação e desejos das mulheres pernambucanas de discutir questões que não tinham espaço nos partidos. "Não faziam parte da agenda dos partidos e sindicatos, daí o nosso interesse de refletir”. São discursos 
que expressam a matriz geradora da participação das mulheres quanto às suas necessidades materiais, históricas e culturais, originárias das lutas das mulheres no campo e na cidade e as formas de interseção dessas organizações de mulheres.

São trajetórias distintas e ao mesmo tempo semelhantes nos problemas que têm a enfrentar, confrontar, negar e /ou afirmar. Trata-se de uma teia de relações que tecem o gênero, a cultura, as relações sociais que produzem e reproduzem as condições materiais de vida.

O feminismo no Nordeste não foi e não é uma construção linear sem conflitos isso porque a diversidade dos processos que se articulam e se complementam, se negam e se reforçam. Além disso, a extensão, impacto e influências recebidas dos diferentes feminismos: da diferença, da igualdade, marxismo refletem nas vidas e na ação práticas de cada uma que por sua vez irá traduzir nas organizações, evidenciam a riqueza e a heterogeneidade desse movimento.

Como percebem essa discussão não se esgota nesta comunicação. A história e memória dos feminismos têm muitas versões que se entrelaçam e se cruzam assumindo um caráter coletivo e democrático a produção do conhecimento a medida que estimula novas formas de pensar e reconstruir parte de uma história que está nos sentidos e na razão de cada uma de nós. É importante, escrever cada parte, cada momento sobre essa história, assim estaremos não somente trazendo para a visibilidade histórias pouco conhecidas, muitas, estigmatizadas, entretanto, são histórias que desde seu nascedouro se impuseram pela essência do conteúdo revolucionário, afirmando suas contribuição através do conjunto das ações que se desenvolveram e favoreceram a implementação de políticas públicas provocando rupturas no pensamento e na prática.

O pensamento feminista oportunizou uma nova leitura da realidade e a "situação social das mulheres passou a ser pensada relacionalmente como relações sociais de sexo ou de gênero por serem fruto das relações de poder e hierarquia entre os sexos”, enfatiza Scavone (2004:37).

Muitas mudanças se processaram nas três últimas décadas, porém os desafios ainda são muitos. Talvez o maior deles seja nos mantermos unidas, acreditando na coerência de nossos discursos e práticas políticas, que passa pela afirmação de um espaço político comum, que comporte toda essa diversidade, aprendizagem e sonhos. Esse espaço desejado e possível são os Fóruns Estadual de Mulheres, é a Articulação de Mulheres Brasileiras, são os Núcleos de Pesquisa das Universidades, são as redes de pesquisadores a exemplo da Rede Feministas de Estudos e Pesquisa sobre Mulher e Gênero - REDOR que se constituem espaços de reflexão e ação capazes de articulador demandas sociais e ao mesmo tempo funcionam como espaço de fortalecimento de nossas identidades feministas que em tempos cada vez mais globalizados e massificados, urge a necessidade de buscar os princípios filosóficos que norteiam as práticas feministas fundamentadas 
Polis, Revista de la Universidad Bolivariana, Volumen 10, $N^{\circ}$ 28, 2011

na construção de uma sociedade sem gênero que respeite as diferenças, contemple nossas diversidades, regionalidades e levem em conta nossos ritmos, processos, tempo político, momento e preocupações. 


\section{Nota}

${ }^{1}$ Marluze Pastor foi integrante do Grupo de Mulheres da Ilha e coordenadora da organização Fórum Carajás, hoje esta engenheira agrônoma é Presidente do IBAMA no Maranhão. 


\section{Bibliografia}

Chaves, Patricia; Severien, Elizabeth (2006), “O feminismo, as mulheres e a Cidade em Pernambuco”. Caderno Feministas de Economia \& Política. Recife, n.3, p.83-116.

Ferreira, Mary (1999), As Caetanas vão à luta; a trajetória do movimento feminista no Maranhão face as políticas públicas. São Luís (Dissertação de Mestrado em Políticas Públicas) Universidade Federal do Maranhão, 269p.

Ídem (2000), “Movimento feminista, movimento de mulheres: ações e desafios para as próximas décadas”. In: Sales, Celecina de Maria Veras; Amaral, Célia Chaves Gurgel do; Esmeraldo, Gema Galgani. Feminismo: memória e história. Fortaleza: Imprensa Universitária, p.69-76.

Ídem (2004), Ser feminina, ser feminista: eis a questão. Jornal O Estado do Maranhão. São Luís, 8 de mar., p. 2. Caderno Opinião.

Schmidt, Simone Pereira (2004), “Como e porque somos feministas”. Estudos Feministas, v. 12, n.e, set./dez. p. 17-21.

Sccavone, Lucila (2004), Dar a vida e cuidar da vida: feminismo e Ciências Sociais. UNESP,. 205p.. São Paulo

Torres, Sandra (2009), Coordenadora da Coordenadoria Municipal da Mulher.Entrevista sobre a ação do movimento feminista no Maranhão, São Luís.

Recibido: 24.01.2011

Aceptado: 03.03.2011 